\title{
Alterações na temperatura do ar mediante telas nas laterais de ambientes protegidos cultivados com tomateiro
}

\author{
Larissa A. D uarte ${ }^{1}$, Edgar R. Schöffel ${ }^{1}$, Marta E. G. Mendez ${ }^{1}$ \& Euclides Schallenberger ${ }^{2}$
}

\begin{abstract}
RESUMO
Este trabalho avaliou a influência do uso de telas anti-insetos nas laterais de ambientes protegidos sobre a temperatura do ar de um cultivo de tomate. 0 experimento foi realizado em Itajaí, SC (270 34' S; 48 30' W), no período de $17 / 03$ a $25 / 07 / 2003$, onde foram instalados quatro ambientes cobertos com filme plástico de PEBD, sendo que um deles não possuía revestimento lateral e três estavam revestidos lateralmente, cada um com um tipo de tela anti-insetos. As telas anti-insetos utilizadas foram: clarite (5 fios por $\mathrm{cm}$ ), citros (10 fios por $\mathrm{cm}$ ) e antiafídeo (20 fios por $\mathrm{cm}$ ). 0 ambiente revestido com tela antiafídeo nas laterais apresentou maiores valores de temperatura máxima do ar durante 0 outonoinverno, o que ocasionou aumento médio de $2,0{ }^{\circ} \mathrm{C}$ na temperatura média diária, quando comparado com 0 ambiente sem tela nas laterais. A variação da temperatura do ar nos ambientes com tela citros e clarite foi semelhante, apresentando ganho térmico diário de $0,4{ }^{\circ} \mathrm{C}$ em relação ao ambiente sem tela anti-insetos e possibilitou condições mais estáveis entre as temperaturas noturna e diurna para o cultivo do tomateiro nessa época do ano.
\end{abstract}

Palavras-chave: tela anti-inseto, ganho térmico, estufa, cultivo orgânico

\section{Changes in air temperature due to side screens of greenhouses cultivated with tomato}

\begin{abstract}
This study aims to assess the influence of insect-proof screens installed in plastic greenhouses cultivated with tomato on the air temperature and crop yield. The experiment was conducted in Itajaí, SC, Brazil ( $27034^{\prime}$ S; 48 $30^{\prime} \mathrm{W}$ ), from $17 / 03$ to $25 / 07 / 2003$. Four greenhouses cultivated with tomato and all covered with polyethylene of low density (PEBD) in the superior part were used. Three of these environments were covered laterally, each one with a different kind of screen: clarite insect-proof screens (12 meshes per $\mathrm{cm})$, citros insect-proof screens $(25$ meshes per $\mathrm{cm}$ ) and afideo insect-proof screens (50 meshes per $\mathrm{cm}$ ). The fourth environment did not receive any side coverage. The covered environment with afideo insect-proof screens on sides presented the highest maximum air temperatures during the autumn-winter period, causing a mean increase of $2.0^{\circ} \mathrm{C}$, in the daily mean temperature, compared with the environment without insect-proof screens. Variations of the air temperature in protected environments with citros insect-proof and clarite afideo insect-proof screens were similar, and showed $0.4{ }^{\circ} \mathrm{C}$ thermal gains in comparison with the without insect-pro of screens, so promoting more regular thermal conditions during nights and days for cultivation of tomato during the autumn-winter period.
\end{abstract}

Key words: insect-proof screens, thermal gain, greenhouse, organic production

Departamento de Fitotecnia da Faculdade de Agronomia Eliseu Maciel (FAEM/UFPel), CEP 96010-900, Pelotas, RS, CP 354. Fone: (53) 3275.7390. E-mail: larhode@yahoo.com.br; ricardo schoffel@ufpel.edu.br; marta@ufpel.edu.br

${ }^{2}$ Empresa de Pesquisa Agropecuária e Extensão Rural de Santa Catarina (EPAGRI), CEP 88301-970 - Itajai, SC, CP 277 Fone: (47) 3341.5255. E-mail: kide@epagri.sc.gov.br 


\section{INTRODUÇÃO}

Para qualquer espécie vegetal, o conhecimento da variação da temperatura do ar no local em que a cultura é cultivada, mostra-se imprescindível, visto que a planta depende dela em todas as suas fases fenológicas. Durante o inverno da região sul do Brasil, faz-se necessária a busca de alternativas de cultivo que minimizem os problemas provocados por temperaturas noturnas e mínimas muito baixas, já que o tomateiro requer temperaturas superiores a $10^{\circ} \mathrm{C}$ e inferiores a $35^{\circ} \mathrm{C}$, e ainda para cada fase do desenvolvimento requer uma faixa ótima de temperatura do ar, ou seja: germinação de 16 a 29 ${ }^{\circ} \mathrm{C}$, subperíodo vegetativo de 20 a $24{ }^{\circ} \mathrm{C}$; floração de 18 a $24{ }^{\circ} \mathrm{C}$; pegamento de frutos de 13 a $18{ }^{\circ} \mathrm{C}$, durante a noite, e de 19 a 25 ${ }^{\circ} \mathrm{C}$, durante o dia e na maturação de 20 a $24{ }^{\circ} \mathrm{C}$, intervalo ideal para a formação do licopeno, substância responsável pela pigmentação vermelha dos frutos (Gómez et al., 2000; Adams \& Valdés, 2002; Alvarenga, 2004).

A temperatura do ar é de extrema importância para o crescimento e desenvolvimento das plantas; é também favorável à presença e proliferação de pragas e doenças; normalmente, isto é o que ocorre em ambientes protegidos, uma vez que os mesmos proporcionam condições favoráveis ao desenvolvimento da planta e, ao mesmo tempo, ambiente favorável às pragas, vetores de doenças e disseminação das mesmas.

O tomateiro é a cultura de maior gasto financeiro com agrotóxicos por área cultivada no Brasil (Neves, 2009) e esse expressivo consumo de agrotóxicos causa grande preocupação quanto aos problemas ambientais decorrentes e com a saúde dos trabalhadores rurais e consumidores (Melo \& Vilela, 2005). Como alternativa a este modelo de cultivo, tem-se a produção orgânica, na qual não são admitidas aplicações de agrotóxicos nem o uso de adubos solúveis e daí decorre a dificuldade no cultivo do tomateiro no sistema orgânico, pelos elevados problemas fitossanitários que a cultura apresenta. A cobertura de polietileno desfavorece a ocorrência de doenças foliares mas não exclui os ataques de insetos-praga, como mencionam Sentelhas \& Santos (1995), Furlan \& Folegatti (2002) e Caliman et al. (2005). Neste sentido, as telas de exclusão de insetos podem viabilizar o controle de pragas em ambientes protegidos cultivados com tomateiro no sistema orgânico de produção, fato avaliado por Schallenberger et al. (2008), os quais concluíram que o uso de telas anti-insetos em abrigos de cultivo, protegem as plantas do ataque de brocas (Agrotis spp, Helicoverpa zea, Spodoptera spp) e da traça do tomateiro (Tuta absoluta).

O uso de telas traz modificações no ambiente de cultivo, pois reduz a taxa de ventilação em razão da sua resistência à corrente de ar. Como consequência, há redução na velocidade dos ventos no interior dos abrigos e aumento do gradiente de temperatura (Beltrão et al., 2002; Furlan \& Folegatti, 2002; Teruel, 2010). A redução da advecção no interior de ambientes protegidos atenua os processos de troca de energia e massa de ar com o ambiente externo provocando, ainda, aumento da umidade relativa do ar (Cunha \& Escobedo, 2003; Reisser Júnior et al., 2003; Teruel, 2010).
Diante do grande desafio que é a produção orgânica de hortaliças em ambiente protegido e acreditando que o uso de tela anti-insetos possa promover vários benefícios a esse sistema de produção, o presente trabalho objetivou avaliar alterações térmicas do ar, provocadas pelo uso de telas antiinsetos nas laterais de ambientes protegidos cultivados com tomateiro, durante o período de outono-inverno.

\section{MATERIAL E MÉTODOS}

O trabalho foi conduzido na área de pesquisa da Estação Experimental da EPAGRI (Empresa de Pesquisa Agropecuária e Extensão Rural de Santa Catarina) de Itajaí (latitude de $27^{\circ} 34^{\prime}$ $\mathrm{S}$, longitude de $48^{\circ} 30^{\prime} \mathrm{W}$ e altitude de $5 \mathrm{~m}$ ). O clima do local é do tipo Cfa, conforme a classificação de Köppen, com temperatura média do mês mais frio (julho) de $15,4{ }^{\circ} \mathrm{C}$ e do mês mais quente (fevereiro) de $24,8{ }^{\circ} \mathrm{C}$, e apresenta chuva total anual de $1755 \mathrm{~mm}$. O cultivo do tomateiro foi realizado de 17/03 a 25/07/2003, em quatro ambientes protegidos, do tipo pampeana, medindo $10,0 \times 7,0 \mathrm{~m}$, com altura de pé direito de 2,0 m e altura da cumeeira de $3,5 \mathrm{~m}$, cobertos com polietileno de baixa densidade (PEBD) com espessura de 100 ìm, orientação Norte-Sul, e sem cortinas laterais e janelas zenitais. Em três desses ambientes foi avaliada a utilização de diferentes telas em suas laterais, colocadas antes do plantio, permanecendo até o final do experimento, enquanto no quarto ambiente o cultivo foi sem presença de tela nas laterais (guarda-chuva).

As denominações dadas aos ambientes cultivados com tomateiro foram: ambiente "sem tela", sem presença de tela nas laterais; ambiente "clarite", com tela anti-insetos do tipo clarite (malha de 2,0 x 2,0 mm com 5 fios por cm de tela, 12 mesh) nas laterais; ambiente "citros", com tela anti-insetos do tipo citros (malha de 1,0 x 1,0 mm com 10 fios por $\mathrm{cm}$ de tela, $25 \mathrm{mesh}$ ) nas laterais; ambiente "afídeo", com tela anti-insetos do tipo antiafídeo (malha de $0,5 \times 0,5 \mathrm{~mm}$ com 20 fios por $\mathrm{cm}$ de tela, 50 mesh) nas laterais.

Nos quatro ambientes foram coletados dados de temperatura do ar através de um sistema de aquisição dos dados (CR10X, Campbell Scientific $($ ) e a temperatura do ar foi medida a cada minuto, individualmente e simultaneamente em cada ambiente, por pares termoelétricos de cobre-constantan, os quais foram instalados na área central de cada ambiente, a 0,70 $\mathrm{m}$ da superfície do solo, observando-se as recomendações de Beltrão et al. (2002) e Furlan \& Folegatti (2002), em que os mesmos obtiveram valores médios diários da temperatura do ar em cada ambiente através da média aritmética de todas as leituras diárias. As temperaturas máximas e mínimas diárias em cada ambiente, foram obtidas a partir dos valores absolutos de medida da temperatura do ar; para o cálculo das temperaturas médias diurnas e noturnas foram selecionados os horários de cada intervalo de tempo (diurno e noturno) a partir do fotoperíodo local. Obteve-se a termoperiodicidade diária pela subtração entre as temperaturas médias diurnas e noturnas.

Os ambientes foram cultivados com tomateiro 'Fortaleza', de crescimento indeterminado, mantendo-se as plantas com 2 $\mathrm{m}$ de estatura através da poda, em que o espaçamento utilizado 
foi de 1,0 m entre as linhas e 0,50 m entre as plantas, com condução vertical e tutores de bambu.

Em todos os ambientes utilizou-se irrigação por gotejamento e se realizaram apenas práticas de manejo, como desbrota, amontoa e poda; a adubação foi realizada somente com compostagem, utilizando-se quantidades recomendadas conforme a análise do solo e a análise dos teores de nutrientes do composto orgânico. $\mathrm{O}$ controle de doenças foi realizado com produtos permitidos pelas normas de produção orgânica de alimentos do Ministério da Agricultura.

\section{RESULTADOS E DISCUSSÃO}

Ao observar a variação das temperaturas máximas diárias desde o transplante até a colheita (Figura 1A) verifica-se, que independente do ambiente, houve tendência de decréscimo da temperatura máxima do ar com o avanço do outono para o inverno, período em que as temperaturas máximas absolutas registradas foram de $46,4{ }^{\circ} \mathrm{C}$ (afídeo), $37,2{ }^{\circ} \mathrm{C}$ (citros), $36,5^{\circ} \mathrm{C}$ (clarite) e $35,6^{\circ} \mathrm{C}$ (sem tela).

As temperaturas máximas mais elevadas do ciclo de cultivo ocorreram quando as plantas estavam no período vegetativo (nos meses de março e abril) e no início do período reprodutivo. Nesses dias críticos quanto à temperatura máxima do ar, a presença lateral das telas anti-insetos do tipo citros e do tipo clarite não acarretou acréscimos consideráveis na temperatura do ar em relação ao ambiente sem tela, conforme pode ser visualizado na Figura 1, porém o emprego de tela antiafideo fez com que, frequentemente, a temperatura máxima ultrapassasse o limite de $35^{\circ} \mathrm{C}$; nos ambientes "sem tela", "clarite" e "citros", esta variável esteve acima de $35^{\circ} \mathrm{C}$ por 1,4 e 7 dias, respectivamente, enquanto no ambiente "afídeo" ocorreram 46 dias com temperaturas acima de $35^{\circ} \mathrm{C}$, significando que em $35 \%$ dos dias do ciclo (130 dias) de cultivo ocorreu temperatura de risco para a cultura. Segundo Alvarenga (2004), sob temperaturas do ar superiores a $35^{\circ} \mathrm{C}$ podem ocorrer danos à cultura do tomateiro como: redução drástica na porcentagem de germinação, morte prematura das plântulas, menor crescimento das plantas, menor aproveitamento de nutrientes e clorose das folhas, queda das flores, prejuízo na polinização, abortamento e queima dos frutos. Temperaturas acima de $40^{\circ} \mathrm{C}$ durante a floração do tomateiro, como aquelas que ocorreram no período de 25 a 28 de abril no interior do ambiente "afídeo", afetam drasticamente a produção de pólen e pegamento dos frutos (EMBRAPA, 2003). Em Eldorado do Sul (latitude: $30^{\circ} 05^{\prime}$ $\mathrm{S}$; longitude: $51^{\circ} 35^{\prime} \mathrm{W}$ ), ao avaliar, em ambientes com cobertura de PEBD com tela anti-insetos cultivados com tomateiro no período de setembro a junho, Reisser Júnior (2002) observou apenas 10 dias com temperaturas acima de $35^{\circ} \mathrm{C}$.

$\mathrm{Na}$ Figura 1B é possível verificar que a oscilação diária da temperatura mínima do ar foi semelhante entre os ambientes até o final de maio, quando estava finalizando o outono. A partir de junho, houve tendência de temperaturas mínimas do ar mais baixas no ambiente "sem tela", atingindo diferença de até $8,9^{\circ} \mathrm{C}$ no dia $05 / 06 / 2003$, quando a temperatura foi de $7,2^{\circ} \mathrm{C}$, valor este inferior à temperatura crítica inferior para a cultura $\left(10^{\circ} \mathrm{C}\right)$. Como o ambiente "sem tela" não possui proteção lateral,
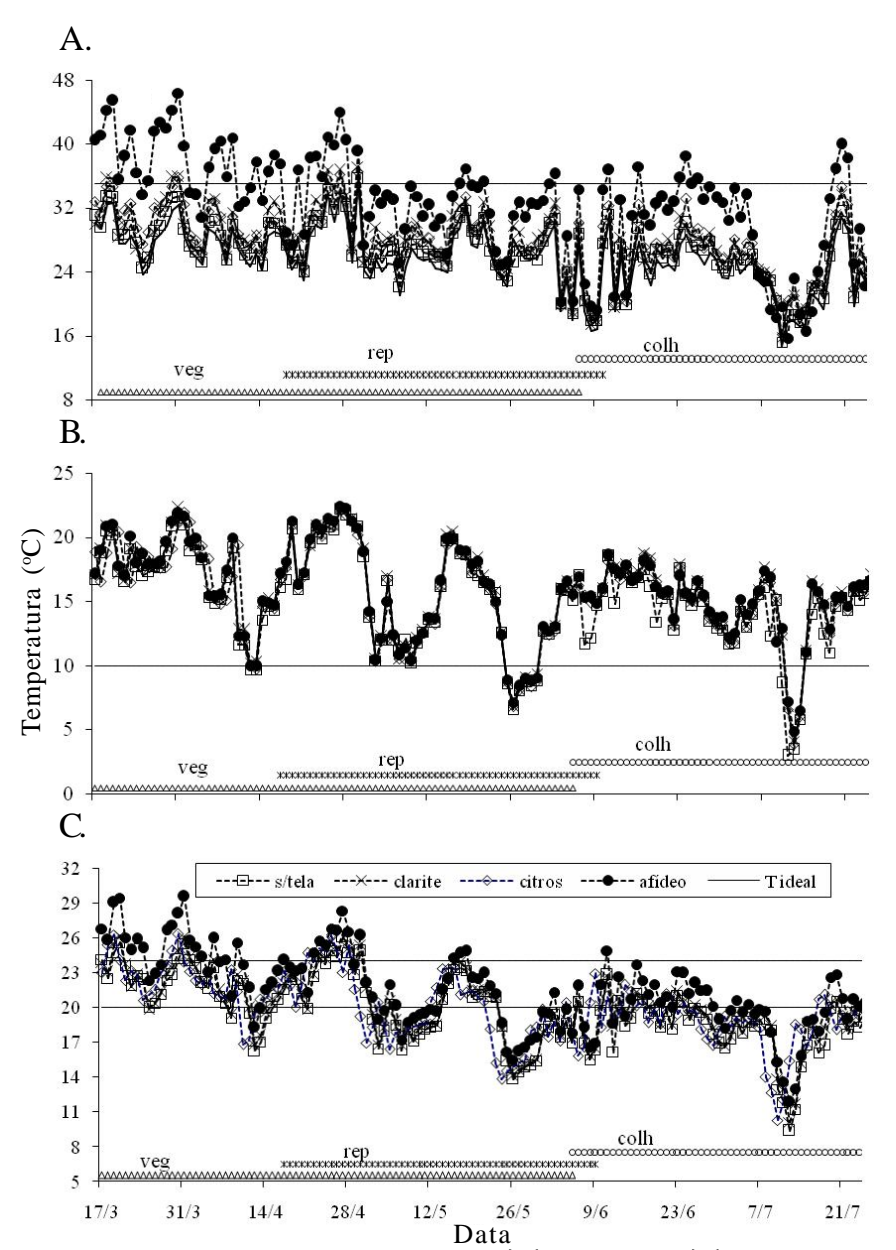

Figura 1. Temperatura máxima $(A)$, mínima $(B)$ e média (C) do ar em ambientes protegidos com cobertura de PEBD e com laterais abertas (s/tela), tela clarite, tela citros, tela antiafídeo, e a temperatura máxima limitante (T cri) para o cultivo da cultura do tomateiro, no período de 17/03 a 25/07/2003, em Itajaí, SC

está mais sujeito à substituição do ar interno (que à noite está mais aquecido) pelo ar externo (que no período noturno possui menor energia) e como consequência os efeitos da inversão térmica foram menores nos ambientes com cortinas laterais do que no ambiente "sem tela"; quanto aos ambientes com tela nas laterais, as temperaturas mínimas mais baixas foram de 11,4 ${ }^{\circ} \mathrm{C}$ nos ambientes "clarite" e "citros", e de $11,6^{\circ} \mathrm{C}$ no ambiente "afídeo". Esses resultados corroboram com aqueles obtidos por Cunha \& Escobedo (2003), Costa et al. (2004) e Fontes et al. (2004) os quais encontraram diferença na temperatura do ar medida no interior de estufas em relação àquela medida em ambiente externo, e também por Reisser Júnior (2002) que, igualmente, observou a ocorrência de temperaturas inferiores em ambiente coberto com PEBD e sem tela lateral do que no ambiente com tela anti-inseto na lateral.

Os efeitos da inversão térmica são mais evidentes em noites com céu límpido e ausência de vento, quando ocorre acentuada perda radiativa da superfície; em decorrência disto e a partir de determinado momento da noite, forma-se uma camada de água condensada na superfície interna do plástico, a qual reduz a permeabilidade do plástico à radiação de ondas longas, de 
modo que ocorre atenuação no esfriamento do ar no interior da estufa, resultando em temperaturas mínimas do ar que, geralmente, permanecem superiores àquelas do ambiente externo. Portanto, a formação desta camada de vapor d'água condensada contribui para o aumento do efeito estufa do plástico sobre as temperaturas mínimas do ar. Em relação aos demais ambientes, pressupõe-se que no ambiente "sem tela" exista maior renovação do ar e, ainda, que a condensação de água junto à superfície interna tenha ocorrido posteriormente à dos demais ambientes.

No interior do ambiente "sem tela" foram registrados 14 dias com temperaturas mínimas abaixo de $10^{\circ} \mathrm{C}$, sendo que o menor valor diário encontrado foi de $3,0{ }^{\circ} \mathrm{C}$; mesmo que não provoquem a morte do tomateiro, essas baixas temperaturas diminuem a velocidade das reações enzimáticas das plantas reduzindo, também, o crescimento e o desenvolvimento das mesmas, conforme destacam Caliman et al. (2005). Nos ambientes com telas nas laterais foram observados 9 dias com temperaturas mínimas abaixo da limitante, sendo que os menores valores registrados em cada ambiente foram de $3,9^{\circ} \mathrm{C}$ (clarite), $4,1{ }^{\circ} \mathrm{C}$ (citros) e $4,9{ }^{\circ} \mathrm{C}$ (afídeo), demonstrando o benefício promovido pela presença de tela anti-insetos, para condições de ambiente com proteção do tipo guarda-chuva (cobertura superior com PEBD), em épocas de maior frequência de temperaturas baixas, como o período de outono-inverno da região Sul do Brasil.

Neste cultivo de outono-inverno do tomateiro em Itajaí, SC, o ambiente sem tela nas laterais apresentou a menor média de temperatura do ar $\left(19,6^{\circ} \mathrm{C}\right)$ e o ambiente com tela afídeo, que possui menor abertura de malha, proporcionou a maior temperatura média $\left(21,6^{\circ} \mathrm{C}\right)$, ou seja, o ambiente com tela afídeo promoveu um acréscimo diário de $2,0^{\circ} \mathrm{C}$ na temperatura média do ar em relação ao ambiente sem telas nas laterais. Os ambientes com tela clarite e com tela citros, ambos com $20^{\circ} \mathrm{C}$, apresentaram $0,4^{\circ} \mathrm{C}$ de ganho em relação ao ambiente sem telas.

Na Figura 1C estão representadas as temperaturas médias diárias dos ambientes cujo maior valor médio para todo o período foi de $29,5^{\circ} \mathrm{C}$, encontrado no ambiente "afídeo" no dia $31 / 03$ e cujo menor valor foi de $9,4{ }^{\circ} \mathrm{C}$ para o ambiente "sem tela", no dia 12/7. Percebe-se ainda que, durante o período vegetativo e boa parte do período reprodutivo, as temperaturas médias dos quatro ambientes permaneceram dentro da faixa ideal para a cultura, porém no final do período reprodutivo e em grande parte do período de colheita, as temperaturas médias foram inferiores às temperaturas ideais, principalmente no ambiente "sem tela", evidenciando que a presença das telas laterais favorece o aumento da temperatura no interior do ambiente, sendo que este aumento de temperatura é uma função da porosidade do material de revestimento de suas laterais e, evidentemente, das condições ambientais externas; desta forma, telas com menor porosidade (menor abertura de malha) constituem uma barreira que limita a renovação do ar e, com isso, diminuem as perdas energéticas armazenadas no seu interior durante o dia, mantendo o ambiente mais aquecido, conforme demonstrado na Figura 1. É interessante observar que, mesmo apresentando temperaturas máximas elevadas
(Figura 1A), o ambiente com telas antiafídeo não alterou a temperatura média diári,a seja nos ambientes "clarite" ou "citros" (Figura 1C).

Como se observa na Figura 2A, a variação da temperatura média do ar no período diurno foi semelhante nos quatro ambientes analisados, porém no ambiente "afídeo" as temperaturas diurnas se mantiveram mais elevadas do que nos demais ambientes, com valores variando entre 15,6 e 33, $5^{\circ} \mathrm{C}$; nos ambientes "clarite" e "citros", a temperatura média diurna variou de 13,0 a $28,3^{\circ} \mathrm{C}$, enquanto no ambiente "sem tela" ela esteve entre 12,0 e $27,8^{\circ} \mathrm{C}$; desta forma, pode-se observar que, durante o período vegetativo, foram mais frequentes temperaturas acima do intervalo ideal $\left(19\right.$ a $\left.25^{\circ} \mathrm{C}\right)$, sendo que no ambiente "afídeo" o afastamento da temperatura diurna em relação à faixa ideal foi maior do que nos demais ambientes avaliados. Durante o período reprodutivo, que envolve o pegamento de frutos e durante a colheita dos frutos, ocorreram alguns dias com temperaturas diurnas pouco acima do intervalo critico ideal definido por Alvarenga (2004), sendo que, à semelhança do ocorrido no período vegetativo, isto se deu com maior ênfase no ambiente "afídeo" do que nos demais ambientes.

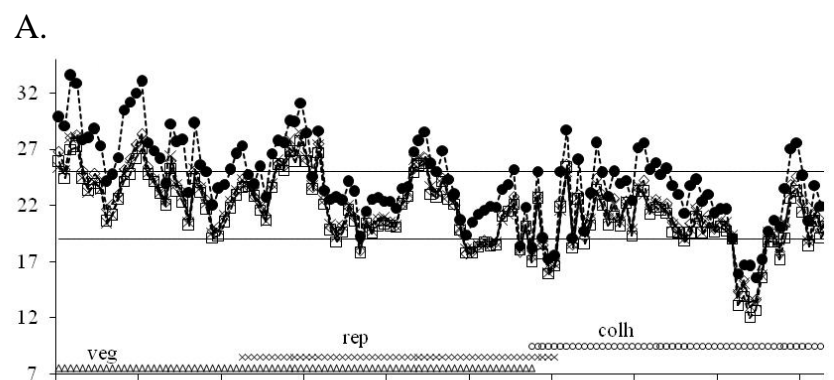

B.
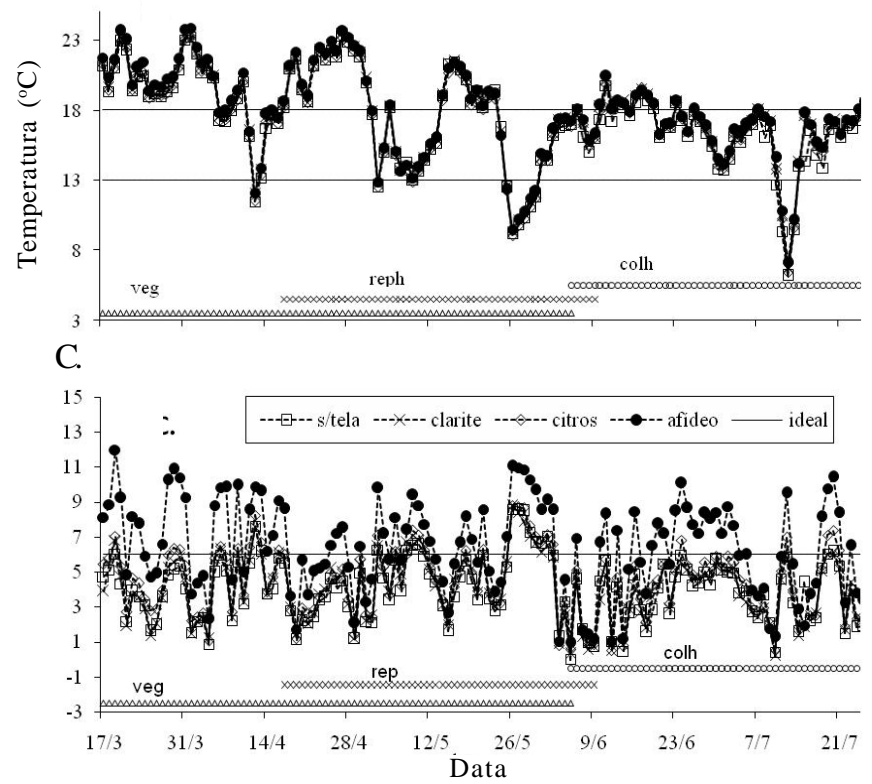

Figura 2. Temperatura média diurna (A) e noturna (B) e termoperiodicidade $(C)$ em ambientes protegidos cobertos com PEBD e com laterais abertas (s/tela), tela clarite, tela citros, tela antiafídeo, e o intervalo ideal de temperatura para o cultivo da cultura do tomateiro, no período de 17/ 03 a 25/07/2003, em Itajaí, SC 
Pela Figura 2 praticamente não é possível identificar diferenças entre as temperaturas médias noturnas dos quatro ambientes durante o período de cultivo do tomateiro. A temperatura noturna mais elevada foi de $23,9^{\circ} \mathrm{C}$ no ambiente "afídeo", e o menor valor foi de $6,2{ }^{\circ} \mathrm{C}$ no ambiente "sem tela", enquanto a maior diferença encontrada em um mesmo dia entre os ambientes "sem tela" e "afídeo", foi de $3,4{ }^{\circ} \mathrm{C}$; para Caliman et al. (2005) esta variável possui grande importância pois, quando a temperatura noturna cai abaixo de $18^{\circ} \mathrm{C}$, a velocidade das reações enzimáticas diminui, reduzindo também o transporte de fotoassimilados sintetizados durante o dia.

De modo geral, em grande parte do ciclo $(60 \%)$ as temperaturas noturnas estiveram fora do intervalo indicado como ideal para a cultura, sendo que na maioria das noites ela esteve acima desse intervalo (Figura 2). Em termos de ambiente ocorreram 59 (sem tela), 60 (clarite), 63 (citros) e 67 (afídeo) noites com temperaturas acima do intervalo ideal $\left(13^{\circ} \mathrm{C}\right.$ a 18 ${ }^{\circ} \mathrm{C}$ ) para a o tomateiro; além disso, observou-se que, em 11 noites nos ambientes "citros" e "afídeo" e em 12 noites nos ambientes "sem tela" e "clarite", as temperaturas foram menores do que o intervalo definido por Alvarenga (2004).

Além dos intervalos ideais de temperaturas noturnas e diurnas, para maximizar o crescimento e a produção de frutos o ideal para o tomateiro é que haja uma termoperiodicidade diária (diferença entre temperatura diurna e noturna) em torno $6,0^{\circ} \mathrm{C}$ (Gómez et al., 2000). No caso do cultivo de outono-inverno de tomateiro em Itajaí, em termos gerais a termoperiodicidade variou entre $0,4^{\circ} \mathrm{Ce} 12,0^{\circ} \mathrm{C}$, conforme pode ser visualizado na Figura $2 \mathrm{C}$. Analisando todo o ciclo da cultura, em média para cada ambiente, a termoperiodicidade foi de $4,0^{\circ} \mathrm{C}$ (sem tela), 4,1 ${ }^{\circ} \mathrm{C}$ (clarite), $4,4^{\circ} \mathrm{C}$ (citros) e $6,4^{\circ} \mathrm{C}$ (afídeo) mas, considerandose uma faixa desvio de $1,0^{\circ} \mathrm{C}$ em relação à termoperiodicidade de $6,0^{\circ} \mathrm{C}$, obtiveram-se 45 registros nos ambientes "clarite" e "citros", 35 registros no ambiente "sem tela" e 30 registros no ambiente "afídeo". Desta forma, as termoperiodicidades observadas nos ambientes "clarite" e "citros" se aproximaram por mais vezes daquelas consideradas por Gómez et al. (2000) e isto evidencia que os ambientes "clarite" e "citros" possibilitaram condições mais regulares entre as temperaturas noturnas e diurnas para o cultivo do tomateiro, nessa época do ano.

Como efeito dessas condições térmicas e se considerando apenas os frutos com características comerciais, constata-se que a produtividade foi de $15,7 \mathrm{t} \mathrm{ha}^{-1}$ no ambiente sem telas laterais, de 28,1 tha $\mathrm{t}^{-1}$ no ambiente com tela tipo clarite, de 34,6 $\mathrm{t} \mathrm{ha}^{-1}$ no ambiente com tela tipo citros e de $22,3 \mathrm{t} \mathrm{ha}^{-1}$ no ambiente com tela tipo antiafídeo (Tabela 1). Esses dados de produtividade sugerem que o uso de telas anti-insetos proporcionou melhorias das condições de cultivo do tomateiro sendo que, em termos relativos, o uso de telas proporcionou um incremento mínimo de $42 \%$ à produtividade do ambiente sem telas laterais, resultados que corroboram com os obtidos por Schallenberger et al. (2008) que obtiveram aumento significativo da produção comercial de tomates em ambientes protegidos lateralmente com telas "clarite", "citros" e "afídeos" e em relação a ambiente com laterais abertas, durante um cultivo de inverno-primavera no mesmo local.
Tabela 1. Produtividade do tomateiro cultivado em ambientes protegidos com cobertura de PEBD e com laterais abertas (s/tela), tela clarite, tela citros, tela antiafídeo, no período de 17/03 a 25/07/2003, em Itajaí, SC

\begin{tabular}{lc}
\hline Ambiente & Produtividade $\left(\mathbf{t ~ h a}^{-1}\right)$ \\
Tela citros & $34,6 \mathrm{a}$ \\
Tela clarite & $28,1 \mathrm{~b}$ \\
Tela antiafídeo & $22,3 \mathrm{C}$ \\
Sem tela & $15,7 \mathrm{~d}$ \\
CV\% & 12,71 \\
\hline
\end{tabular}

Médias seguidas da mesma letra não diferem estatisticamente a nível de $5 \%$ de probabilidade, pelo teste de Duncan; PEBD (polietileno de baixa densidade)

\section{ConClusões}

1. Para as condições de cultivo de tomateiro no interior de ambientes cobertos com PEBD durante o outono-inverno, o uso de revestimento lateral com tela anti-insetos proporciona ganho térmico ao ambiente.

2. Ambientes cobertos e com telas anti-insetos do tipo citros e clarite apresentam variação térmica diária semelhante, sendo que telas do tipo antiafídeos proporcionam maiores acréscimos diários à temperatura mínima, máxima e média do ar.

3. No ambiente sem tela nas laterais e com cobertura de PEBD, as baixas temperaturas são mais frequentes do que em ambiente com tela nas laterais e com cobertura de PEBD.

4. Os intervalos de temperatura recomendados para o cultivo do tomateiro durante o período outono-inverno são mais comuns no interior de ambientes cobertos com PEBD e com proteção lateral de telas do tipo citros ou clarite do que em ambientes com telas laterais do tipo anti-insetos ou sem telas laterais.

\section{LITERATURA CITADA}

Adams, S. R.; Valdés, V. M. The effect of periods of high temperature and manipulating fruit load on the pattern of tomato yields. The Journal of Horticultural Science \& Biotechnology, v.77, p.461-466, 2002.

Alvarenga, M. A. R. Produção em campo, em casa de vegetação e em hidroponia. Lavras: UFLA, 2004. 400p.

Beltrão, N. E. de M.; Fideles Filho, J.; Figueirêdo, I. C. M. Uso adequado de casa-de-vegetação e de telados na experimentação agrícola. Revista Brasileira de Engenharia Agrícola e Ambiental, v.6, p.547-552, 2002.

Caliman, F. R. B.; Silva, D. J. H.; Fontes, P. C. R.; Stringheta, P. C.; Moreira, G. R.; Cardoso, A. A. Avaliação de genótipos de tomateiro cultivados em ambiente protegido e em campo nas condições edafoclimáticas de Viçosa. Horticultura Brasileira, v.23, p.255-259, 2005.

Costa, E.; Leal, P. A. M.; Carmo Júnior, R. R. Modelo de simulação da temperatura e umidade relativa do ar no interior de estufa plástica. Engenharia Agrícola, v.24, p.57-67, 2004.

Cunha, A. R.; Escobedo, J. F. Alterações micrometeorológicas causadas pela estufa plástica e seus efeitos no crescimento e produção da cultura do pimentão. Revista Brasileira de Agrometeorologia, v.11, p.15-26, 2003. 
EMBRAPA - Empresa Brasileira de Pesquisa Agropecuária, Cultivo de tomate para industrialização. 2003. <http:// sistemasdeproducao.cnptia.embrapa.br/FontesHTML/ Tomate/TomateIndustrial/clima.htm>: 27 Jan. 2010.

Fontes, P. C. R.; Loures, J. L.; Galvão, J. C. C.; Cardoso, A. A.; Mantovani, E. C. Produção e qualidade do tomate produzido em substrato, no campo e em ambiente protegido. Horticultura Brasileira, v.22, p.614-619, 2004.

Furlan, R. A.; Folegatti, M. V. Distribuição vertical e horizontal de temperaturas do ar em ambientes protegidos. Revista Brasileira de Engenharia Agrícola e Ambiental, v.6, p.93-100, 2002.

Gómez, O.; Casanova, A.; Laterrot, H.; Anais, G. Mejora genética y manejo del cultivo de tomate para la producción en el Caribe. La Habana: Instituto de Ivestigaciones Horticolas "Liliana Dimitrova", 2000. 159p.

Melo, P. C. T.; Vilela, N. J. Desafios e perspectivas para a cadeia brasileira do tomate para processamento industrial. Horticultura Brasileira, v.23, p.154-157, 2005.

Neves, E. M. Dispêndios com defensivos agrícolas no qüinqüênio 1997-2001. <http://www.abbabatatabrasileira. com.br/revista06_018.htm>12 Mar. 2009.
Reisser Júnior, C. Alterações físicas em ambientes de estufa plástica e seus efeitos sobre as condições hídricas do tomateiro. Porto Alegre: UFRGS, 2002. 160p. Tese Doutorado

Reisser Júnior, C.; Bergamaschi, H. ; Radin, B. ; Bergonci, J. I. Alterações morfológicas do tomateiro em resposta à redução de radiação solar em ambientes de estufa plástica. Revista Brasileira de Agrometeorologia, v.11, p. 7-14, 2003.

Schallenberger, E.; Rebelo, J. A.; Mauch, C. R.; Ternes, M.; Pegoraro, A. Comportamento de plantas de tomateiros no sistema orgânico de produção em abrigos de cultivo com telas anti-insetos. Revista de Ciências Agroveterinárias, v.7, p.23-29, 2008.

Sentelhas, P. C.; Santos, A. O. Cultivo protegido: Aspectos microclimático. Revista Brasileira de Horticultura Ornamental, v.1, p.108-115, 1995.

Teruel, B. J. Controle automatizado de casas de vegetação: variáveis climáticas e fertigação. Revista Brasileira de Engenharia Agrícola e Ambiental, v.14, p.237-245, 2010. 